\title{
EDUCAÇÃO E TRABALHO NA RETÓRICA EMPRESARIAL: a atualização do ethos fordista
}

\author{
Antonia de Lourdes Colbari*
}

\begin{abstract}
A proposta do estudo parte de uma tese antiga que, na atualidade, ganhou novas significações e se converteu em uma panaceia. Trata-se da relação entre educação, desenvolvimento e modernização da sociedade, uma tríade que demanda, em escala cada vez mais ampliada, o fomento da escolaridade, da inovação e da inclusão social. O suporte empírico para a análise foi extraído de documentos técnicos divulgados pela CNI (Confederação Nacional da Indústria) e considerados emblemáticos para explicitar a configuração das proposições e de traços significativos do sistema de crenças e de valores da cúpula empresarial da indústria brasileira. A despeito das singularidades conjunturais, o resultado evidenciou uma linha de continuidade no que se refere à relação entre educação, inovação e desenvolvimento, bem como ao papel que esse segmento empresarial almeja desempenhar na economia, na constituição e organização do mercado de trabalho e nos processos de modernização social.

PALAVRAS-CHAVE: Educação. Trabalho. Desenvolvimento. Instituições empresariais. Ethos fordista.
\end{abstract}

Uma síntese inicial deste ensaio se expressa da seguinte forma: a educação e a qualificação para o trabalho se tornaram o pivô de uma construção discursiva que legitima percursos formativos mais consistentes e, ao mesmo tempo, flexíveis, nos quais se enfatiza o desenvolvimento de saberes e de competências múltiplas, ambos continuamente atualizados, em resposta às exigências da sociedade do conhecimento e da inovação e à instabilidade do mercado de trabalho. E mais: além de escolarizar e (ou) qualificar, trata-se de formar um habitus, de refinar os processos socializadores ("civilizadores"), tradicionalmente associados às funções da educação, como bem mostra a seguinte afirmação:

... formar capital humano [na visão empresarial] significa não apenas preparar as pessoas nas respectivas profissões, mas também investir na formação de hábitos e atitudes positivas em relação ao trabalho, à vida comunitária e ao regime democrático (CNI, 2007, p. 38).

* Doutora em Sociologia. Professora da Universidade Federal do Espírito Santo e Bolsista de Produtividade em Pesquisa do CNPq, nível 2.

Av. Fernando Ferrari s/n. Goiabeiras. Cep: 29075-015 - Vitoria - Espírito Santo - Brasil. alcolbari@terra.com.br
Registra-se, na atualidade, o revigoramento de uma velha questão, porém agora apresentada com novos contornos, maior visibilidade, revestida de outras significações e exaltada como panaceia para todos os problemas sociais. Tratase da relação entre educação, desenvolvimento e modernização da sociedade, incluindo-se, nesse processo, a elevação da escolarização e da qualidade de vida da população. O investimento em educação e a produção de conhecimentos aparecem como "pilares críticos" nos esforços realizados para se potencializar a capacidade de inovação e de competitividade das empresas, bem como da economia do país, razão pela qual merecem destaque nos discursos das elites políticas e empresariais.

É inegável a influência da Teoria do Capital Humano, popularizada por Theodore Schultz e Gary Becker, no consenso produzido em torno da premente necessidade de se investir em educação e, por esse vetor, também em ciência e tecnologia, sob a ameaça de exclusão do circuito econômico global, no qual o "trabalho do conhecimento" se tornou a principal força produtiva 
(Fontenelle, 2012). Na "sociedade do conhecimento", o "capital humano" se torna o "principal ativo das empresas", e "[...] é formado pelo conjunto de habilidades [...] adquiridas por meio de processos educativos, treinamento ou da experiência. As chamadas competências básicas, formadas pela educação básica e a continuada, são condição para o desenvolvimento das demais competências, inclusive as profissionais." (CNI, 2005, p. 22) e para a continuidade e o aperfeiçoando profissional ao longo da vida.

Visto como investimento (e não mais "gasto"), o aumento ou aprimoramento do "capital humano" introduz a educação no centro das políticas de desenvolvimento e, ao mesmo tempo, legitima os gastos públicos no setor (López-Ruiz, 2004). Também merece registro o fato de que as recentes mudanças intraorganizacionais demandam pessoas que, na avaliação do Instituto Herbert Levy (apud Oliveira, 2003, p. 257), reúnam, em um grau mais avançado, "educação, formação profissional e capacidade intelectual" (“[...] todos dentro da fábrica têm que saber cada vez mais [...]"), e que sejam aptas para atuar em um contexto menos hierarquizado e mais dependente da criatividade, da iniciativa e da responsabilidade. Sugere o referido texto, estar ficando superada a "[...] fábrica dos capatazes autoritários e dos operários semiqualificados [...]", pois não é mais “[...] esta fábrica que impulsiona os países para as áreas mais interessantes e lucrativas [...]". Assim, se o baixo nível de escolaridade se torna disfuncional ao sistema produtivo, pois "assinar o nome e ler frases muito simples não impactam positivamente a produtividade da economia", também provoca efeitos excludentes no acesso ao mercado:

[...] a grande maioria da população economicamente ativa [se torna] inabilitada para operar em uma economia moderna, em que as competências de expressão escrita estão intimamente imbricadas com o desempenho profissional, mesmo em ocupações manuais (CNI, 2006, p. 135).

No entanto, o tributo à teoria do Capital Humano não exclui os novos significados associ- ados às concepções de educação e de desenvolvimento. Cabe lembrar que as interações de fatores sociais, culturais e políticos desenham a matriz do desenvolvimento sustentável, superando a concepção economicista de desenvolvimento, derivação automática do crescimento econômico impulsionado pela criação e incorporação do progresso técnico e pelos ganhos de produtividade. Por sua vez, conteúdos como preparação para o exercício da cidadania, desenvolvimento de aptidões e cultivo de talentos para a vida produtiva e para a vida social, a autonomia, a consciência social e o raciocínio lógico, crítico e criativo são destacados como parte da concepção de educação. A educação se tornou uma "prioridade nacional" pelos “[...] efeitos benéficos que tem sobre a realidade social e econômica [...]", sendo "[...] uma das condições básicas para a construção de uma economia mais eficiente e de uma sociedade mais justa" (CNI, 1997, p. 28).

Por esse viés de uma concepção de educação, associada à inovação, à inclusão produtiva e social e à cidadania, o presente estudo incorpora, no seu escopo analítico, as tentativas dos empresários com vistas à afirmação de um padrão hegemônico ancorado no setor industrial. Indícios desse projeto se fazem presentes nas posições assumidas frente ao poder executivo e nas disputas nas arenas parlamentar e social, em particular nos esforços para mobilizar os segmentos da esfera pública, da esfera privada e do chamado "terceiro setor" em torno das ações de formação e de qualificação profissional. A educação, como proposta mobilizadora assumida pelos empresários, sinaliza a presença de referências simbólicas que extrapolam as fronteiras delimitadas pelo mercado. Nesse caso, além das evidentes provas das falhas do mercado como agência reguladora e como gerador de efeitos sociais equilibrados, também conceitualmente são cada vez mais relevantes os indícios de suas insuficiências para explicar uma dinâmica social que não se reduz às relações econômico-mercantis, porém as incorpora (Granovetter, 1985; Swedberg, 2004). Reconfigura-se a relação entre 
o econômico e o social: o econômico não se reduz ao mercantil e ao monetário, e o social vai além da concepção de distribuição e de gastos sociais, para se tornar "capital social" e "investimento social" (Lévesque, 2007).

Nesta análise, um conjunto de ferramentas conceituais é acionado no esforço de entendimento das mudanças nos valores empresariais, valendo-se tanto das abordagens de caráter mais histórico, que capturam e analisam os movimentos dos empresários na arena política, quanto daquelas que armam uma plataforma conceitual adequada ao tratamento compreensivo do engajamento de suas instituições na "causa" da educação.

Iniciando-se pelas referências históricas, cabe lembrar que o protagonismo do Estado no processo de constituição do capitalismo brasileiro não minimiza a relevância da atuação dos empresários nesse processo, inclusive no eixo da formação para o trabalho assalariado e, recentemente, também nas ações dirigidas à qualificação para os diversos arranjos de trabalho fora do assalariamento. Segundo Diniz (1996, 2000), no período de 1930 a 1990, o empresariado brasileiro não ocupou a posição hegemônica no tocante à formulação e à imposição de um projeto de desenvolvimento capitalista, mas demonstrou elevada capacidade de influenciar as políticas econômicas setoriais, sobretudo pelo trânsito na burocracia pública e interlocução direta com o poder executivo, desfrutando de uma situação privilegiada em relação aos demais atores sociais. Movido pelo pragmatismo, o setor empenhou seu apoio aos "diferentes governos e distintos regimes políticos”; foi um dos eixos de "[...] sustentação política do modelo nacional-desenvolvimentista, em seus diferentes desdobramentos, integrando as diversas coalizões políticas de apoio à ordem industrial" (Diniz, 2010, p. 102).

A partir de década de 1980, em contraste com os períodos anteriores, em que procurava afirmar a sua influência e poder de negociação nas arenas do Poder Executivo, observa-se "um expressivo deslocamento da ação dos interesses organizados” do empresariado para a arena congressual, movimento que exigiu a adequação de sua "estrutura de representação de interesses às mudanças do perfil institucional do país" (Diniz, 2010, p. 111). A década seguinte seria um momento marcante de inflexão na trajetória do capitalismo brasileiro, sinalizado, em particular, pela exaustão do nacional-desenvolvimentismo e pelo imperativo da "[...] inserção-integração das economias nacionais numa estrutura de poder de escopo transnacional marcada por fortes assimetrias econômicas e políticas" (Diniz, 2010, p. 116). Nesse cenário, observa-se o declínio da capacidade do empresariado nacional do setor industrial na definição das estratégias de desenvolvimento, aumentando-se, por outro lado, o "confinamento tecnocrático das decisões" (Bresser-Pereira; Diniz, 2009). Para Mancuso (2004), a inflexão liberal no ambiente econômico e seus desdobramentos, entre eles a abertura comercial, instigam a mobilização política dos empresários, que conseguem superar os obstáculos de ação coletiva, típicos de grupos heterogêneos, e articulam uma agenda em prol de medidas capazes de elevar a competitividade das empresas, sobretudo daquelas relacionadas à redução do custo Brasil.

Em conjunto, fatos de natureza econômica, como o esgotamento do nacional-desenvolvimentismo, a abertura e estabilização da economia e a reestruturação da indústria, foram acompanhados por uma nova visão, uma nova mentalidade empresarial, cujos indícios, no que tange aos parâmetros econômicos, são:

[...] as estratégias competitivas voltadas para inovação tecnológica e diferenciação de produtos; as mudanças estruturais e organizacionais; adequação a normas e padrões internacionais via inovação tecnológica; inovação vista como fundamental para o desempenho exportador; e internacionalização com foco na inovação tecnológica (Arbix; Di Negri, 2005, p. 21).

Porém, apesar do peso dos fatores econômicos nos avanços registrados na organização e na mobilização dos empresários, a dimensão 
política foi marcante, indicando significativas alterações na socialização política, como afirmação de "[...] valores, regras e práticas democráticos, incluindo a aceitação do princípio da alternância do poder [...]" e a predominância do "[...] pragmatismo doutrinário-ideológico, caracterizado por sucessivas adaptações a posturas de maior ou menor alinhamento com um papel mais ativo do Estado" (Diniz, 2010, p. 102). Nestes últimos anos, a presença mais forte da coordenação do Estado da ordem econômica, novamente redireciona a atuação política empresarial para as instâncias burocráticas do poder executivo, paralelamente a um movimento de consolidação e diversificação das entidades de representação de interesses empresariais, configurando uma estrutura organizacional complexa de convivência entre as organizações.

No que diz respeito à formação para o trabalho, historicamente, a inserção na produção e circulação de bens e serviços e a capacidade de interferir nos processos decisórios, na definição de políticas governamentais, tanto em âmbito localizado quanto macrossocial, garantiram aos empresários o poder de influência, ainda que de forma pontual, nas diversas modalidades de educação, embora seu foco tenha sido o ensino profissional. Foi notória a atuação do setor na definição do modelo de ensino profissional que, na década de 40, culminou com a criação do SENAI e do SESI e, posteriormente, das demais instituições integrantes do Sistema S. De inspiração fordista, o Senai articulava conteúdos técnicos e ideológicos na criação de uma pedagogia do trabalho industrial direcionada a desenvolver as competências profissionais básicas e a difundir um conjunto de valores, atitudes e crenças que favoreciam a interiorização da ética do trabalho (Colbari, 1995). Em diferentes conjunturas, as razões econômicas foram utilizadas para justificar os nexos entre a educação e o sistema produtivo, favorecendo as "relações complementares entre o setor empresarial e o governamental" (Silva; Souza, 2009, p. 784).

Uma breve recapitulação das mudanças ocorridas nos processos de qualificação profissional e nas relações estabelecidas entre a escola e o setor produtivo distingue, nas últimas décadas, três diferentes estratégias que, todavia, não se definiram excluindo as precedentes: até 1980, quando ainda predominavam as práticas tayloristas-fordistas, as empresas acionavam as universidades, as escolas técnicas e o Sistema $\mathrm{S}$ para a qualificação de seus profissionais; no momento seguinte, a novidade foi a organização de setores internos de treinamento voltados para a capacitação e o desenvolvimento dos funcionários, tendo em vista a adaptação às mudanças, técnicas e organizacionais; e, a partir da década de 1990, destacaram-se as iniciativas da própria empresa direcionadas para as escolas públicas, como atestam as aproximações com a chamada "comunidade externa" (o bairro, o município ou a unidade federativa) e também pela constituição de escolas no espaço da empresa, viabilizadas por meio de parcerias com os governantes ou com o SESI (Rodrigues, 1998; Quartiero; Bianchetti, 2005).

Não é um fenômeno excepcional a habilidade social dos empresários em influenciar a definição de programas e projetos educacionais recentes, como também não o é a sua condição de ator estratégico capaz de mobilizar diferentes segmentos sociais e persuadi-los a cooperarem em prol da educação (Fligstein, 2007). Atualmente, ilustram o primeiro caso as interferências do setor no Programa Nacional de Educação e na reformulação do ensino médio e profissional, e o segundo, a presença no movimento Todos pela Educação. Um recuo na história destacaria o papel desempenhado por esse segmento na elaboração de políticas educacionais no quadro institucional do regime militar, após 1964. Apenas a título de ilustração, menciona-se o caso do Instituto de Pesquisas de Estudos Sociais (IPES), fundado em 1961 por um grupo composto por empresários, profissionais liberais e elementos das forças armadas, que elegia a educação escolar como fator relevante tanto para o desenvolvimento econômico quanto para o desenvolvi- 
mento social (Souza, 1981).

Compreender as nuanças mais significativas das relações entre os empresários e a educação exige um enquadramento teórico que permita decifrar a configuração de ideias (aspectos cognitivos) e valores (aspectos normativos) - o repertório de representações legítimas e de esquemas de pensamento embutido nas construções discursivas reproduzidas nos documentos técnicos consultados. São construções que interpelam uma diversidade de universos - economia, política e ética -, configurando modelos de ordem legítima, sustentados por uma concepção de interesses perseguidos pelos atores, os quais incluem gratificações econômicas, mas também as simbólicas, entre elas, a busca de afirmação da autoridade e de reconhecimento no espaço público. Nesse esforço, a reflexão se apropria de categorias conceituais de vários autores emblemáticos, entre eles, Bourdieu (2000), Boltanski e Thévenot (1991) e Boltanski e Chiapello (1999), cuja operacionalização permite explorar as dimensões interativas que produzem e são reproduzidas pela reatualização do ethos fordista (Gramsci, 1984).

$\mathrm{O}$ corpus da pesquisa se constitui de documentos técnicos divulgados pela Confederação Nacional da Indústria (CNI) que, desde sua origem, vem se constituindo em um complexo organismo de representação do empresariado industrial brasileiro, capaz de aglutinar a vontade coletiva desse segmento e realizar a intermediação de seus interesses, por meio de uma expressiva habilidade para influenciar o poder Executivo e o Legislativo e a opinião pública (Rodrigues, 1998). Fundada em 1938, a CNI é a instância superior da representação industrial e congrega federações estaduais dotadas de estruturas administrativas próprias e com relativa independência na formulação de projetos, incluindo as ações pedagógicas. Porém, as diretrizes da CNI norteiam as ações das federações estaduais que, no campo educacional, atuam por meio da tríade Senai, Sesi e IEL.

Alguns documentos técnicos foram con- siderados emblemáticos nessa tarefa de explicitar a capacidade de formulação e de intervenção das elites empresariais do setor industrial brasileiro na contemporaneidade, sobretudo o seu interesse em influenciar as ações, a gestão e o desempenho das instituições de ensino. Assim sendo, vários textos publicados nos últimos vinte anos pela CNI foram analisados, embora tenha sido reservado um tratamento especial aos mais recentes, em particular os seguintes: Educação para a nova indústria: uma ação para o desenvolvimento sustentável do Brasil (2007), como desdobramento do Mapa estratégico da indústria, que é uma visão de futuro do País (20072015); a série Agenda legislativa da indústria, ${ }^{1} \mathrm{e}$ os documentos encaminhados aos candidatos à eleição para o Executivo Federal - Competitividade e crescimento: a agenda da indústria (1998); $A$ indústria e o Brasil: uma agenda para o crescimento (2002); Crescimento: a visão da indústria (2006); e A indústria e o Brasil: uma agenda para crescer mais e melhor (2010).

Tanto a Agenda, cujo foco é direcionado para as proposições legislativas em tramitação no Congresso Nacional quanto o documento analítico e propositivo encaminhado aos candidatos à presidência expressam posições consensuais construídas por meio de contribuições de inúmeros empresários e das instituições empresariais da indústria (federações e associações setoriais). Posteriormente, essas contribuições são debatidas nos Conselhos Temáticos da CNI. Em ambas as modalidades de documentos, evidenciam-se preocupações, demandas e formulações que demonstram a grande capacidade da estrutura de representação corporativista de interferir na agenda pública (Mancuso, 2004).

Alem da representação corporativa de interesses setoriais, a CNI tem assumido uma atuação política propositiva nas diferentes instâncias de tomada de decisões públicas e na forma-

${ }^{1}$ A Agenda legislativa da indústria é organizada e publicada anualmente, desde 1996, coordenada pela CNI e realizada pela RedIndústria, uma rede de organizacões empresariais da qual fazem parte a CNI, as federaçốes da indústria de todas as Unidades da Federação e outras associações setoriais de abrangência nacional (Mancuso, 2004). 
ção da opinião pública, tendo em vista aglutinar forças a favor de objetivos políticos mais amplos, como a educação, a inovação, o desenvolvimento sustentável e a redução das desigualdades sociais. Portanto, o padrão de ação política desses atores não se limita à reação às contingências econômicas; são eles portadores de projetos políticos específicos (Mancuso; Oliveira, 2006), pelos quais estão dispostos a mobilizar segmentos da sociedade para além de sua base de representação.

A análise dos documentos selecionados ancorou-se em dois eixos temáticos: o primeiro, a relação entre educação e inovação; o outro, o papel da indústria e de seus empresários como atores decisivos do processo de desenvolvimento e da modernização da sociedade. A partir desses eixos, a reflexão se arma tendo em vista a compreensão dos significados das ações desencadeadas em dois planos. No plano mesossocial, observa-se o empenho dos empresários industriais em se afirmarem como um ator estratégico hábil (Fligstein, 2007), cuja ação se pauta por uma racionalidade, tendo em vista a defesa de interesses específicos. Porém isso não se realiza sem o esforço socializador, a constituição de identidades coletivas capazes de motivar e de persuadir os demais atores à cooperação e ao envolvimento. No caso analisado, o recorte são as ações a favor de uma educação adequada aos desafios econômicos, sociais e políticos do presente. No plano macrossocial, identificam-se as intenções dos empresários em afirmarem uma postura de autoridade e de reconhecimento nas arenas políticas, mirando a sustentação de uma posição hegemônica ancorada no setor industrial.

\section{EDUCAÇÃO E INOVAÇÃO: pilares do desen- volvimento e da promoção social}

No eixo educação e inovação, os documentos técnicos analisados priorizam duas linhas de ação: a educação básica e a educação como qualificação para o trabalho. Na tentativa de resga- tar momentos significativos de um processo discursivo, algumas temáticas são pontuadas.

A primeira refere-se à constatação da fragilidade do sistema educacional e de sua inadequação para a formação dos recursos humanos demandados pelo setor produtivo. Os ainda elevados índices de analfabetismo e a baixa qualidade da educação brasileira impõem limites ao aproveitamento da capacidade da força de trabalho, tal como exigida pelo novo paradigma produtivo e seus elevados patamares de competitividade, indispensáveis tanto para garantir a participação do Brasil nos mercados mundiais quanto para expandir o mercado interno (CNI, 1988). Outro ponto crítico é o distanciamento entre o sistema educacional e “... as verdadeiras necessidades geradas nas atividades econômicas, "[...]situação que tende a se agravar, pois a introdução de novas técnicas de produção eleva a demanda por trabalhadores mais qualificados, aptos para funções complexas" (CNI, 1988, p. 19), em geral, os "talentos cultivados pela via da educação” (IPEA, 2006, p. 124). Esse diagnóstico se repete em vários documentos técnicos produzidos pela entidade e mantém estreita sintonia com a retórica de organizações como a Cepal (1992) United Nations (1996), na qual é nítida a crítica aos modelos tradicionais de educação, acusados de impotência na formação de indivíduos mais autônomos e capazes de se relacionarem com as novas tecnologias demandadas pelas práticas produtivas.

Em 1993, o documento Educação básica e formação profissional: uma visão dos empresários (CNI, 1993) destacava a dependência existente entre a elevação da produtividade e da competitividade das empresas do setor, inclusive nos ramos tradicionais, em relação aos patamares de educação de nível fundamental e médio, sendo essa última articulada à formação profissional. Nesse mesmo ano, Albano Franco, então presidente da CNI, reitera a estrita associação entre a modernização da economia e a democratização da educação. E, se o grande desafio da produtividade estava na formação e no 
aperfeiçoamento do capital humano, era imperativo aos empresários investirem mais na educação básica, que, articulada com a formação profissionalizante, teria impacto na redução do desemprego e abasteceria a indústria com mão de obra mais qualificada (Franco, 1993, p. 3).

Além das vantagens econômicas da escolarização e da formação para o trabalho, observam-se os desdobramentos para a ordem social. Das mudanças substanciais na condução das políticas educacionais dependem as possibilidades de articulação entre desenvolvimento econômico e justiça social, pois o sistema educacional deveria ser capaz de promover a redução das desigualdades sociais, assegurando

... a educação dos desfavorecidos, para que eles desenvolvam suas potencialidades e não sejam destinados, desde os primeiros anos da escolarização, a formar a categoria de perdedores, na concorrência de um mercado voltado para a modernização baseada no desenvolvimento de níveis cada vez maiores de conhecimento (CNI, 1993, p. 8).

A qualidade da educação se transformaria em uma poderosa arma de combate às desigualdades sociais, pois garantiria mais igualdade via inclusão social. Mas, para cumprir o papel de alavanca econômica e social, a formação geral, em nível fundamental e médio, necessitava ser reformulada, inclusive para alicerçar a educação profissional e, assim, constituir as competências múltiplas a serem atualizadas continuamente em resposta às exigências da sociedade do conhecimento (Guilhon, 2005).

Em suma, o patamar e as mudanças das tecnologias tornam o aprendizado profissional mais dependente da educação básica: o suporte de conhecimentos e habilidades relacionados à aptidão de leitura e de interpretação, capacidade de expressão e de trabalho em grupo "[...] na resolução de problemas relativamente complexos [...]"; domínio de conceitos científicos e matemáticos abstratos, recursos para "[...] entender e usufruir das potencialidades tecnológicas do mundo que nos cerca [...]”; e “[...] principal- mente [...] aprender a aprender, condição indispensável para poder alcançar as mudanças e avanços cada vez mais rápidos que caracterizam o ritmo da sociedade moderna." (Silva Filho, 1996, p. 88). Demanda-se

\begin{abstract}
[...] um trabalhador que pensa. [...] aquele que tem um conjunto de conhecimentos básicos e treinamento especifico. A virtude estará em que você tenha um sujeito que conheça muitas coisas, conheça bem as coisas básicas e que possa ser capaz de agir sem receber ordens. [...] Para o trabalhador, portanto, o nível de exigência é que tenha conhecimentos básicos e resolva seus problemas [...] o dia a dia está ali, feito pelos trabalhadores que têm iniciativa, sabem o que têm que fazer, têm o conhecimento. O trabalhador que não tomar decisões, ou porque não tem skill, que é isto que nós estamos falando, é ter esses conhecimentos básicos, ou porque não foi treinado e não compreendeu que faz parte das atividades dele pensar e agir, esse está fora, não tem lugar para ele (Franco apud Rummert, 2000, p. 93).
\end{abstract}

No terreno da qualificação profissional, o discurso da CNI incorpora as noções de competência e de polivalência. O conceito de competência norteia a reforma do ensino médio e da educação profissional brasileira, definindo a necessidade de uma base de conhecimentos que sustente o desenvolvimento das competências profissionais exigidas pela contínua implantação de novas tecnologias nos setores produtivos (Brasil, 1997). A definição de competências se refere às "operações mentais, cognitivas, sócio-afetivas ou psicomotoras" que, ao serem apropriadas pelos educandos, geram habilidades e configuram um "[...] saber fazer que não é produto de uma instrução mecanicista, mas de uma construção mental que venha a incorporar novos saberes, viabilizando, assim, uma requalificação ou uma reprofissionalização em função das mudanças econômicas e tecnológicas.” (Brasil, 1997, p. 13). E uma das formas de gerar e refinar as competências dos recursos humanos é a garantia do acesso à educação básica, sendo ela o alicerce da educação profissional.

Vinculado ao conceito de competências, aparece o de empregabilidade, definido “[...] não apenas como capacidade de obter um emprego, 
mas também de se manter em um mercado de trabalho em constante mutação.” (Brasil, 1995, p. 9). A sintonia entre o sistema de ensino e a aquisição das competências necessárias à empregabilidade é utilizada para justificar a “[...] participação efetiva do empresariado na determinação dos conteúdos que devem ser ministrados durante a realização do processo de formação profissional” (Oliveira, 2001, p. 196).

No discurso da CNI, a noção de polivalência reporta a um tipo de trabalhador capacitado para atuar em diferentes postos de trabalho dentro de uma mesma "família ocupacional”, mas também à independência profissional. Os percursos formativos devem propiciar o desenvolvimento do pensamento teórico e abstrato, da capacidade de "[...] analisar, de pensar estrategicamente, de planejar e de responder criativamente a situações novas”, e também das "[...] capacidades sócio-comunicativas" necessárias à promoção do "trabalho cooperativo em equipe” (CNI, 1993, p. 9).

Não menos importante, nesse debate, é a integração da questão educacional à agenda de "modernização" das relações trabalhistas, com vistas a assegurar a flexibilidade no mercado de trabalho. A redução do custo da mão de obra e a elevação do investimento em educação estimulariam a criação de novas possibilidades de inserção produtiva dos trabalhadores; uma formação profissional mais densa facilitaria aos trabalhadores a circulação entre as ocupações, o que contribuiria para reduzir o componente estrutural do desemprego (CNI, 1995).

Nesse mesmo teor, o documento Emprego na indústria (CNI, 1997, p. 28-29) atribui ao modelo econômico adotado a responsabilidade pela elevação dos índices de desemprego na década de 90 e reafirma que a criação de empregos depende do ambiente macroeconômico, mas também da redução do custo da mão de obra e das políticas ativas de trabalho, sobretudo as de qualificação profissional e de requalificação profissional, capazes de "[...] minorar os impactos da introdução das novas tecnologias sobre o ní- vel de emprego". Assim “[...] o treinamento dos desempregados, visando à sua recolocação no mercado de trabalho em postos de maior qualificação, é uma das principais políticas destinadas a reduzir o desemprego [atual]”, “[...] caracterizado como essencialmente tecnológico".

Constatava-se que, diante das transformações ocorridas em âmbito mundial nos setores produtivo, social e político, nas últimas décadas do século XX, a sociedade brasileira fora desafiada a mudar o padrão de desenvolvimento industrial. Nesse contexto, a indústria precisava buscar mercados externos, o que dependia de sua competitividade, por sua vez, dependente da incorporação do progresso técnico e de um novo patamar de escolaridade e formação profissional do trabalhador (CNI, 1998).

O sucesso das empresas, em um ambiente marcado pela crescente competição e por fortes mudanças tecnológicas, está cada vez mais associado à sua capacidade de implantar modelos de gestão baseados na mobilização das capacidades humanas dos seus colaboradores, obtendo permanente flexibilidade e inovação como condição de competitividade. Nesse cenário, a educação básica assume um papel estratégico para o desenvolvimento das empresas e de uma economia competitiva. [...] O conceito de formação para o trabalho sofreu profundas modificações nos últimos anos. Hoje, a formação de competências e habilidades requeridas pelo mundo do trabalho exige níveis cada vez mais altos de escolarização e formação básica, compreendendo-se nesta o ensino fundamental e o médio. Este conceito certamente não inibe o desenvolvimento de cursos de curta duração, com vistas à formação de habilidades específicas, desde que associados a componentes de habilidades básicas. (CNI, 1998, p. 55).

Em outras palavras, a viabilidade do investimento intensivo em tecnologia depende da qualidade do capital humano que, por sua vez, está atrelada à "qualidade da educação" - a condição para se elevar a bagagem cognitiva e as habilidades operacionais e comunicativas dos trabalhadores. As políticas de qualificação profissional se justificam pela sua função estratégica para a economia, tendo em vista as modificações ao longo do tempo pelas quais passaram as atividades do setor produtivo (Guilhon, 2005).

Em 2005, registra-se a divulgação de um importante documento - o Mapa estratégico da indústria: 2007-2015 (2005a ou 2005b) - do qual 
se extraiu o texto Educação para a nova indústria. Realizado pela CNI e incorporado pelas federações estaduais, esse estudo reflete o peso do crescimento industrial do país na diminuição dos níveis de desemprego, assim como a preocupação com os impactos sobre as competências requeridas para o trabalho e sobre os perfis profissionais, decorrentes da contínua mudança nos processos produtivos desencadeada pela incorporação crescente de tecnologia. Nesse documento, reitera-se a importância da educação para a sustentação de um processo de desenvolvimento econômico e social, pois ela seria

[...] uma das vertentes fundamentais para o crescimento da economia, seja pelo efeito direto sobre a melhoria da produtividade do trabalho formação de trabalhadores mais eficientes, capital humano - seja pelo aumento da capacidade do país de absorção e geração de novas tecnologias (CNI, 2005, p. 10).

A elevação da qualificação profissional pressupõe uma formação mais densa em conteúdos científicos e culturais. Propõe-se o reforço ao ensino de ciências, estimulando os educandos à "[...] apropriação dos conhecimentos da física, da química e da biologia com suas particularidades metodológicas[...]" e para o exercício de atividades de pesquisa, experimentação, descoberta e a validação (CNI, 2007).

Ainda nesse vetor, a proposta de escola de tempo integral é outra ferramenta para melhorar a qualidade da educação, pois a ampliação da jornada escolar favorece, nas diversas modalidades de ensino, a articulação de ações incluindo o ensino-aprendizagem, a cultura, o esporte e o lazer. Refinam-se os processos socializadores e civilizadores, como ilustra a seguinte afirmação:

A escola de tempo integral atualiza o conceito de currículo, possibilitando ao aluno adquirir hábitos de vida saudáveis, ampliar o capital cultural, incentivar a leitura, conhecer novos idiomas, participar de processos de inclusão digital e de formação profissional (CNI, 2007, p. 23).

Em outro fragmento do referido texto, rei- tera-se essa vocação civilizadora da educação, inclusive da profissional, percebida como "um conceito que ultrapassa os limites da escola”, além de ser "a maneira de emancipar o indivíduo pelo trabalho", o que justifica o projeto educacional do SENAI: "[...] formação de cidadãos capazes de atuar de maneira autônoma, crítica, consciente e participativa no ambiente de trabalho e na vida cotidiana [...]" (CNI, 2007, p. 29). No caso específico do setor industrial, além da elevação da escolaridade básica de forma coordenada com educação profissional, a proposta é a "Educação Continuada do Trabalhador da Indústria”, como um “[...] processo permanente de aprendizado e de incorporação de conhecimentos gerados pelo progresso científico e tecnológico, propiciando o desenvolvimento pessoal e profissional" (CNI, 2007, p. 24).

Outra fonte documental relevante para o entendimento do envolvimento da CNI no campo da educação é a Agenda legislativa da indústria. Nos anos de 2008 a 2011, a Agenda destaca o desafio da qualidade como prioridade do sistema educacional brasileiro. "A indústria necessita de recursos humanos qualificados, criativos e com capacidade empreendedora. Essa é a base para a elevação da produtividade e crescimento sustentável da renda" (CNI, 2010a, p. 169). As condições para o "salto qualitativo [do país] em todos os níveis" pressupõem atingir os seguintes objetivos: garantia da qualidade da educação básica; fortalecimento da educação profissional e tecnológica e de "[...] uma educação superior de qualidade e adequada às necessidades da economia do conhecimento e do sistema produtivo"; promoção da inclusão digital; promoção da "cultura empreendedora" e difusão de "valores de livre iniciativa e ética empresarial” (CNI, 2010a, p. 170).

Reiteram-se, nas agendas propostas anualmente ao Poder Legislativo, as demandas apresentadas ao Poder no Executivo, no momento das eleições presidenciais. Em síntese, as propostas-chave são:

1. Universalização e qualidade da educação básica, com foco no "[...] ensino de leitura, escri- 
ta e literatura; matemática; e ciências. [...] Ler, escrever, falar, ouvir, usar números, pensar e resolver problemas são a essência da educação" (CNI, 2010b, p. 152).

2. Superação do "[...] modelo de ensino médio eminentemente acadêmico e voltado para um processo de seleção universitária generalista, evoluindo para um modelo que permita a diversificação de conteúdos e a profissionalização dos indivíduos" (CNI, 2010b, p. 153).

3. Expansão e fortalecimento da educação profissional por meio do "[...] crescimento da oferta de ensino médio em articulação com a educação tecnológica e a formação profissional”; e aperfeiçoamento da "educação profissional na perspectiva de formação continuada” (CNI, 1998, p. 55).

4. Educação superior diversificada em seu formato (incluindo a ofertas de cursos superiores de curta duração, de tecnologia e sequenciais), de qualidade e adequada às necessidades da economia do conhecimento e do sistema produtivo; ampliação da contribuição da universidade para o "[...] desenvolvimento da competitividade industrial, tanto através dos programas de formação e aperfeiçoamento quanto das pesquisas tecnológicas e projetos cooperativos” (CNI, 1998, p. 56); valorização, na mesma intensidade, da educação teórica e prática; e produção de graduados mais criativos e preparados para a prática da inovação e para a adaptação às mudanças constantes nos respectivos campos de trabalho (CNI, 2010b).

Esse elenco de desafios no campo da educação se coaduna com uma das teses mais presentes nos documentos técnicos da CNI: "A educação é a base para a produtividade e inovação", estando ambas (a educação e a inovação) no "[...] DNA dos casos de sucesso de empresas brasileiras que se tornaram mais competitivas nos mercados nacional e internacional" (CNI, 2010b, p. 19). A seguir, são citados fragmentos de textos plenos de conteúdos que associam a alavancagem da inovação aos processos educativos, em seus diversos níveis e modalidades.
O grau de capacidade de um país de adquirir novas tecnologias ou, sobretudo, produzi-las, depende do nível de educação de seus trabalhadores, o que requer ações expressivas nas áreas de educação básica e especializada. Não é suficiente investir na produção de novas ideias - invenção. É necessário que essas ideias sejam postas em prática - inovação. Do contrário o esforço em ciência, pesquisa e desenvolvimento não se traduzirá em ganhos de produtividade e, consequentemente, em crescimento. (CNI, 2002, p. 56).

A nossa força de trabalho sofre os limites resultantes de um grau de escolaridade inferior ao desejado e muitas vezes obtido em um ensino de baixa qualidade. A este quadro desfavorável, soma-se a crescente exigência de qualificação que deriva da introdução das novas tecnologias. A pressão sobre o sistema educacional terá que ter respostas tanto no âmbito do ensino básico como do ensino técnico e profissionalizante, cuja oferta deverá estar cada vez mais adequada à efetiva demanda do mercado e às necessidades de educação continuada. A Universidade, responsável pela imprescindível formação de recursos humanos qualificados e por boa parte da geração do conhecimento, deverá buscar caminhos de maior autonomia e maior compromisso com a produtividade. (CNI, 2002, p. 60).

O baixo nível educacional da força de trabalho é um dos principais limitadores do crescimento do Brasil. Com a aceleração da taxa de inovação tecnológica mundial, possuir mão de obra educada - capaz de absorver e melhorar as novas tecnologias - é crucial para o desenvolvimento econômico do País. (CNI, 2006, p. 132).

A educação não só é importante para o uso de novas tecnologias como é insumo indispensável para sua criação. Sem uma população com alto nível de escolaridade, um país não consegue passar do estágio de apenas absorvedor de novas tecnologias para criador e, consequentemente, acelerar seu crescimento. (CNI, 2006, p. 132).

O País deve proporcionar os incentivos necessários para incutir na sociedade a ideia de crescimento individual, como resultante da busca pelo conhecimento. Assim, uma boa política educacional deve estar conjugada a crescimento econômico, de modo que se criem ambientes de trabalho propícios ao uso das competências adquiridas. (CNI, 2006, p. 133).

Se a carência de trabalhador qualificado compromete o aumento da produção e da produtividade e a própria competitividade do país, torna-se imperativa uma agenda "positiva e prioritária" que supere as deficiências educacionais. Sem enfrentar esse desafio, ficam compro- 
metidos tanto os esforços de inovação - sendo essa uma "variável estratégica das empresas brasileiras" - quanto aqueles de promoção do desenvolvimento social e de redução das desigualdades. Romper-se-ia a cadeia virtuosa de benefícios gerais: aumento da produtividade, novas oportunidades de empreendedorismo, criação de empregos e elevação da remuneração de investidores e de trabalhadores (CNI, 2002; CNI, 2006).

No que se refere à oferta de educação superior, os documentos da CNI (2009, p. 206; 2010a, p. 171) destacam sua inadequação e insuficiência para atender os "[...] crescentes níveis de exigência e de complexidade no trabalho e em função das inovações tecnológicas e das novas formas de organização da produção". A adequação da educação superior ao "projeto de Nação" exige prioridade de determinados aspectos: pesquisas em "[...] áreas consideradas essenciais para o desenvolvimento socioeconômico, industrial e tecnológico [...]" e a "[...] formação tecnológica voltada a profissões emergentes e decorrentes da constante inovação gerada no setor produtivo [...]", principalmente "[...] os cursos de graduação e pós-graduação nas engenharias, ciências exatas e biológicas [...]"; estímulos à pesquisa colaborativa, criatividade, inovação, empreendedorismo, espírito crítico e rigor acadêmico-científico; e flexibilidade dos "[...] modelos para possibilitar conteúdos programáticos adequados aos níveis de desenvolvimento científico e tecnológico demandados pelo setor produtivo, pelo processo de inovação e pela competitividade internacional".

Além do aperfeiçoamento qualitativo de todos os níveis de ensino e da adaptação de seus conteúdos às exigências da sociedade e do setor produtivo, reivindica-se um Plano Nacional de Pós-Graduação com prioridade para as áreas do conhecimento mais próximas das demandas da construção de uma plataforma de ciência e tecnologia capaz de estimular o processo de geração e de inovação tecnológica. Além de sintonia com essas demandas, a expansão dos cursos de pós-graduação deveria contemplar o desenvolvi- mento das regiões com indicadores sociais, econômicos, culturais ou científicos inferiores à média nacional (CNI, 2008; CNI, 2010a).

Reivindica-se a presença mais forte da ação estatal nos investimentos em ciência e tecnologia, pois, apesar de reconhecer as empresas como as principais forças inovadoras de um país, a ação do governo é decisiva para a criação de um sistema nacional de inovação que inclua os centros produtores de conhecimento (universidades e demais instituições de pesquisa) e agentes econômicos públicos e privados (CNI, 2002). No viés schumpeteriano, a inovação é alçada à condição de principal força produtiva para garantir a racionalidade capitalista moderna e depende do fluxo de ideias. Assim sendo,

[...] a atividade produtora de ideias, isto é, atividade que compreende pesquisa e desenvolvimento, gera externalidades positivas. Ideia é um importante insumo para a produção de novas ideias. Portanto, quanto maior o estoque de ideias disponíveis, maior a produtividade no setor de pesquisa e desenvolvimento (CNI, 1998, p. 77).

Por sua vez, a produção de ideias é cada vez mais dependente da pesquisa cientifica e das possibilidades de transferir sua aplicação para o tecido produtivo. Dessa forma, a produção e o domínio de conhecimentos e tecnologias deixam de ser encarados apenas pelo ângulo do mercado e sob a perspectiva da utilização imediata e se convertem em questões políticas, de cunho estratégico, sobre as quais se requer a função reguladora do Estado: "[...] a produção de ideias (novos processos de produção, produto, design e tecnologia), devido às suas especificidades, é uma atividade econômica que demanda intervenção direta e normativa do governo" (CNI, 1998, p. 77).

Além da aproximação entre as exigências do setor produtivo e a estrutura e o funcionamento do sistema educacional, as ações de governo deveriam estimular os investimentos privados em P\&D, via isenção fiscal: a política tecnológica deveria incluir a redução de barreiras à importação de tecnologia (CNI, 2007; CNI, 2010b). Reivindicam-se do governo medidas de 
estímulo ao desenvolvimento tecnológico, por meio de uma atuação

[...] tanto na provisão de um ambiente indutor ao investimento em $\mathrm{P} \& \mathrm{D}$ e à inovação, como na qualificação da mão de obra, fazendo uso de um adequado sistema de incentivos e apoios voltados para o setor produtivo (CNI, 2002, p. 61).

Em resumo, as percepções empresariais sobre a educação destacam a obrigação estatal de garantir uma contínua formação profissional adequada ao perfil do trabalhador produzido pela acumulação flexível. Ou seja: capacitação para o enfrentamento da permanente instabilidade do mercado de trabalho e a universalização da educação básica, que deve ser complementada pela formação profissional, em diversos níveis, acompanhando toda a vida produtiva do trabalhador.

Apesar do reconhecimento do papel do Estado no desenho e na operacionalização do sistema educacional, percebe-se, nos documentos analisados, a insistência na necessidade de as organizações empresariais contarem com um "sistema próprio e compulsório de financiamento de formação profissional", tendo em vista o período de duração e a complexidade da "formação de recursos humanos de alta qualificação". O caráter compulsório e a participação ativa dos empresários na sustentação de um sistema de ensino ou de capacitação profissional são considerados cruciais para viabilizar processos formativos adequados ao abastecimento do mercado de mão de obra qualificada nas novas práticas produtivas que envolvem várias áreas do conhecimento, "muita assistência pessoal", "estabilidade, continuidade e planejamento de longo prazo" e foco nas tendências do mercado e das mudanças tecnológicas. A precisão desse foco demanda agilidade, flexibilidade e ajustes contínuos nos processos de formação (CNI, 2005c).

Nesse sentido, mais uma vez, a influência de Schultz (1973) se evidencia. A educação não se desprende de seu caráter de investimento direcionado à aquisição de conhecimentos e capacidades operacionais, técnicas e gerenciais decorrentes dos avanços científicos e tecnológicos incorporados e (ou) estimulados pela dinâmica do sistema econômico. Como porta de entrada para as inovações tecnológicas, em decorrência da premente necessidade de atualizar seu ciclo produtivo, a indústria tem seu destino atrelado à própria capacidade de assimilar e produzir inovação, o que coloca em relevo outra característica do setor: a demanda de formação de uma mão de obra qualificada, capaz de absorver e acompanhar as mudanças na tecnologia. Portanto, a defesa de investimentos crescentes em educação tem foco: um tipo de educação direcionada a produzir os recursos humanos úteis ao funcionamento do setor produtivo. E, no padrão atual de desenvolvimento econômico da sociedade brasileira, a produção desses recursos impõe a elevação da escolaridade em geral, mas também em nichos específicos que incrementem a formação de profissionais de nível técnico e de nível superior nas áreas tecnológicas.

Em sintonia com essas demandas e refletindo a capacidade de influência do empresariado sobre as decisões governamentais, situa-se o plano Brasil Maior, lançado em 2011 pela presidência da república, cujas dimensões sistêmicas reiteram a necessidade de formação e de qualificação profissional em sintonia com as demandas do crescimento econômico baseado na inovação. Serão apoiados, no âmbito federal, os programas educacionais destinados ao ensino técnico profissionalizante e às engenharias, entre eles o Programa Nacional de Acesso à Escola Técnica (Pronatec), o Plano Nacional Pró-Engenharia e o Programa Ciência sem Fronteiras. ${ }^{2}$ No âmbito da iniciativa privada, o SENAI receberá apoio do governo para ampliar e construir "novos centros de pesquisa e de formação profissionalizante con-

\footnotetext{
O programa Ciência sem Fronteiras concede bolsas para estágios no exterior, destinadas a alunos de graduação e pós-graduação, e também para pesquisadores de empresas. As áreas prioritárias do programa são: Engenharias e demais áreas tecnológicas; Ciências Exatas e da Terra; Biologia, Ciências Biomédicas e da Saúde; Computação e Tecnologias da Informação; Tecnologia Aeroespacial; Fármacos; Produção Agrícola Sustentável; Petróleo, Gás e Carvão Mineral; Energias Renováveis; Tecnologia Mineral; Biotecnologia; Nanotecnologia e Novos Materiais; Tecnologias de Prevenção e Mitigação de Desastres Naturais; Biodiversidade e Bioprospecção; Ciências do Mar; Indústria Criativa; Novas Tecnologias de Engenharia Construtiva; e Formação de Tecnólogos.
} 
forme as novas necessidades da indústria nacional” (Brasil, 2011, p. 14).

Em seu escopo geral, o Brasil Maior expressa a pauta da indústria captada por meio da análise dos documentos técnicos da CNI, preparando o terreno para análise proposta neste artigo, no tópico a seguir. Definido como “[...] um esforço integrado e abrangente de geração de emprego e renda em benefício do povo brasileiro [...]" (Brasil, 2011, p.7), o foco do Plano é o “[...] estímulo à inovação e à produção nacional para alavancar a competitividade da indústria nos mercados interno e externo" e, dessa forma, permitir "[...] passos mais ousados em direção ao desenvolvimento econômico e social". O esforço para "mobilizar as forças produtivas para inovar, competir e crescer" (Brasil, 2011, p. 7) envolve ações transversais e setoriais visando ao aumento da eficiência produtiva da economia como um todo, esforço que demanda o aproveitamento das competências desenvolvidas no interior das empresas, das instituições acadêmicas e na sociedade em geral (Brasil, 2011).

\section{A "VOCAÇÃO" DA INDÚSTRIA: o ethos fordista}

Inicia-se o desenvolvimento deste tópico com a seguinte constatação: faz parte do sistema de crenças do empresariado do setor industrial a ideia de que a visão empreendedora, "forjada a partir dos desafios da economia real", sustenta uma "liderança catalisadora" e faz dos empresários "agentes do desenvolvimento e da mudança”, cuja ação pode ter influências positivas de alcance mais amplo, como no processo de elaboração e de implantação de políticas públicas e na mobilização da sociedade a favor da modernização da economia e das instituições brasileiras (CNI, 2005c, p. 21).

"O País que queremos" é um dos enunciados em destaque nos textos analisados, nos quais a defesa da competitividade da economia aparece associada a outros fatores: geração de emprego e renda, institucionalidades e marcos regulatórios ade- quados ao desenvolvimento, à sustentabilidade e à inovação. A seguir, algumas citações ilustrativas:

A elevação da competitividade é o eixo central da agenda de desenvolvimento industrial. É o caminho mais eficaz para privilegiar a produção e a geração de empregos no País. [...] A indústria brasileira confia em sua capacidade de responder aos desafios de um mundo em mutação [...]. Mas, para o prosseguimento do êxito da sua missão, entende ser imprescindível que o ambiente externo às empresas deixe de representar uma desvantagem competitiva (CNI, 1998, p. 6).

Superar o viés anticompetitividade das políticas e instituições e recuperar o caminho do crescimento sustentado é a rota mais eficaz para privilegiar a produção e a geração de empregos no Brasil (CNI, 1998, p. 9).

Queremos consolidar o Brasil como uma economia competitiva e inovadora, capaz de crescer de forma sustentável e gerar mais e melhores empregos. Queremos uma economia inserida na sociedade do conhecimento, reconhecida como uma das principais plataformas da indústria mundial (CNI, 2006, p. 19).

Em outros trechos dos documentos analisados, a percepção dos empresários sobre o impacto da indústria na economia brasileira e na vida social está associada aos princípios e à efetivação de uma economia competitiva "puxada" pelo setor industrial, ambos associados às crenças nas supostas potencialidades virtuosas das empresas, na democracia, na redução das desigualdades regionais e nos propósitos de gerar empregos e reduzir a pobreza e a desigualdade social.

A indústria brasileira tem ambição. A sua visão de Brasil é a de um País capaz de superar a pobreza e desigualdade sobre as bases de uma sociedade democrática e de uma economia de mercado competitiva (CNI, 2002, p. 11).

A agenda do crescimento vai além da estabilidade e do respeito aos fundamentos econômicos. $\mathrm{O}$ crescimento precisa ser conscientemente buscado. É um trabalho árduo. [...] Exige visão estratégica, ações em múltiplas direções e coalizões políticas com capacidade de garantir a sua implementação, integrando empresas, setores e regiões às oportunidades de crescimento mais dinâmicas (CNI, 2002, p. 11).

A indústria e o Brasil querem crescer. O baixo crescimento da economia nos últimos dez anos dificulta a capacidade de o País gerar empregos e criar uma sociedade mais justa. A única forma sustentável de gerar riqueza é por meio do setor privado. Um clima de investimentos desfavorável desestimula os em- 
preendedores e cria obstáculos à criação dos empregos que financiarão os gastos sociais e os serviços que beneficiam a sociedade. A máquina do crescimento são as empresas (CNI, 2006, p. 14).

A CNI tem uma visão de longo prazo para o País: é o Mapa Estratégico da Indústria (2007-2015). O Mapa define objetivos, metas e programas, capazes de consolidar o Brasil como uma economia competitiva, inserida na sociedade do conhecimento e base de uma das principais plataformas da indústria mundial: inovadora, com capacidade de crescer de forma sustentável, com mais e melhores empregos (CNI, 2006, p. 17).

Ainda nessa trilha, a publicação CNI (2010, p. 11) apresenta uma síntese do que seria "crescer mais e melhor": "desenvolver-se de forma sustentada"; "reduzir a pobreza e a desigualdade"; "preservar a sustentabilidade ambiental"; e "garantir a diversificação e transformação da estrutura produtiva”.

A "ambição" da indústria está alicerçada em um sistema de crenças e valores (elaborações cognitivo-normativo-valorativas), incluindo a convicção quanto à sua capacidade para liderar o crescimento sustentado da economia brasileira e no reconhecimento de sua força transformadora, uma dinâmica que irradia efeitos sobre os demais segmentos do sistema produtivo. Essa crença se reforça diante da constatação de que os países com ritmos de crescimento expressivos e sustentáveis têm, na indústria manufatureira, a fonte de dinamismo (CNI, 2010c). São vários os fatores que sustentam a importância da indústria: geração de riquezas, empregos e divisas e vanguarda na produção e difusão tecnológica, com impacto nos demais setores da economia. Nessa trilha, são sugestivos os fragmentos de texto citados a seguir;

[...] a indústria tem um papel estratégico. Nos últimos anos ela buscou a produtividade e a eficiência. [...] A afirmação do Brasil como um dos principais polos manufatureiros da economia mundial exigirá também uma crescente inovação de processos e produtos, uma política deliberada de abertura de mercados externos e a capacidade de beneficiar-se da aplicação das modernas tecnologias de informação (2002, p. 12). É falsa a visão de que com o crescimento dos serviços a perda da importância da indústria seria uma tendência irreversível. Esta tese é fruto, dentre outras razões, de ilusão estatística. Com a terceirização parte do emprego e valor que era gerado diretamente pela indústria passou a ser contabilizado no setor serviços. Parcela importante dos serviços existentes nas economias desenvolvidas é direta e indiretamente resultante de um setor industrial expressivo. [...] É básico, portanto, reconhecer que um projeto de desenvolvimento não pode prescindir da consolidação de um setor industrial dinâmico. (CNI, 2002, p. 13).

Não existe um modelo único de crescimento para os países. Mas, respeitadas as peculiaridades de cada um - os recursos naturais, o nível de educação, a qualidade do capital humano -, há um padrão na trajetória exitosa do crescimento, que é à base da indústria manufatureira. [...] A produção e a exportação de manufaturas constituem o caminho mais viável para a transição de uma economia de baixa renda para outra de renda média ou alta. Essa é a conclusão do Relatório de Desenvolvimento Industrial das Nações Unidas, de 2009, baseado na experiência de 159 países, 121 dos quais em desenvolvimento (CNI, 2010, p. 14, grifos do autor).

As proposições da CNI, ancoradas em um projeto de desenvolvimento no qual a indústria ocupa um lugar estratégico, não parecem reiterar as teses sobre a suposta debilidade política do setor empresarial brasileiro, alvos das críticas de Diniz (2000), Mancuso (2004), e Mancuso e Oliveira (2006). Faz parte dessa investida da CNI, no sentido de afirmar um projeto de desenvolvimento, a defesa da mudança nos marcos reguladores, considerados inibidores da iniciativa econômica, pois a elevação da competitividade envolve decisões relativas às estratégias das firmas do ambiente em que elas estão inseridas. Envolveria "um novo tipo de ativismo que se defronta com estruturas do Estado despreparadas", com capacidade limitada de promover a coordenação das "ações necessárias à elevação da competitividade”, que se encontram dispersas e compartimentadas em várias instituições (CNI, 2002).

As condições favoráveis ao desenvolvimento são também vistas como dependentes da qualidade e do aperfeiçoamento do arcabouço institucional, da existência de regras claras e seguras que incentivem mecanismos de autorregulação ou de corregulação entre os próprios empresários e 
assegurem o fortalecimento do espírito empreendedor. Esse aperfeiçoamento envolve várias ações: mudanças na legislação tributária e trabalhista (já comentadas neste artigo); desburocra-tização, transparência e eficiência da gestão pública; segurança jurídica e eficiência do judiciário; defesa da concorrência e da propriedade intelectual, segurança pública; e o aperfeiçoamento permanente do sistema político (CNI, 2005; Martinelli, 2009).

Nessa retórica, torna-se mais nítido o papel que os empresários industriais reservam ao Estado na ordem econômica. Investido pelo sistema constitucional-legal da condição de princípio coordenador ou regulador, a ele cabe: mobilizar e organizar a ação dos agentes produtivos; garantir a regência das leis de mercado; e criar ou preservar um ambiente político-institucional favorável ao aumento de produtividade e eficiência econômica. As crenças no livre mercado não excluem a necessidade de marcos reguladores institucionalizados, de legislação clara, "as regras do jogo", e o incentivo a determinados padrões de comportamento. Em suma: reafirma-se a importância de uma institucionalidade que defina a matriz de incentivos e de sanções, além de reduzir a margem de incertezas e de custos, assegurando a estabilidade das relações, a segurança dos contratos e das transações (Condé, 2006).

Mas, se essas demandas enunciam interesses particulares do setor, a bandeira da educação favorece a aproximação entre o específico e o geral. A representação da educação como panaceia já é senso comum, fortemente presente no imaginário coletivo, sendo reconhecida como uma via legitima de mobilidade social e uma forma de combate à pobreza e à marginalidade. E mais: é uma condição vital tanto para sustentar a competitividade da economia nos mercados globais, cada vez mais exigentes de conhecimentos e de inovação, quanto para se construir uma sociedade pautada por parâmetros de justiça, de igualdade (pelo menos de oportunidade) e de reconhecimento social. Assim sendo, tornam-se cada vez mais sedutores os discursos que "[...] professam a educação como a propulsora do desenvolvimento econômico e social dos países ditos periféricos e a colocam como prioridade, em termos quantitativos e qualitativos, nas ações da esfera governamental e empresarial." (Silva; Souza, 2009, p. 784) E não se deve desprezar o fato de que está em causa uma reivindicação histórica de movimentos sociais, de partidos políticos e de sindicatos, que, em tese, são opositores à ordem econômica vigente.

Essa forte representação da educação no imaginário social impregna as instituições que compõem o aparato produtivo-administrativo das empresas e o aparato estatal, em suas estruturas objetivas e cognitivas (Bourdieu, 2000), e contribui para sedimentar o processo de legitimação de certas práticas de intervenção social. No caso das instituições empresariais, é possível identificar o processo apontado por Habermas (1987) de busca pela legitimação comunicativa dessas instituições, ou seja: a legitimidade da ação estratégica depende de sua sujeição aos imperativos da razão comunicativa, tornando o discurso institucional, aqui representado pelos documentos técnicos divulgados pela CNI, uma peça relevante para se compreenderem as conexões entre as estratégias econômicas, o poder político e o reconhecimento social. A análise desses textos contribuiu para desvendar aspectos do universo de significação dos empresários - a configuração de interesses e de ideias que alimenta as suas motivações e demarca o quadro cognitivo-valorativo subjacente às percepções a respeito das articulações entre mercado, sociedade e estado. Dessas percepções derivam as construções discursivas eivadas de crenças e significados compartilhados e que são utilizadas para a mobilização de diversos segmentos sociais, tendo em vista a obtenção de recursos institucionais necessários ao fomento do desenvolvimento econômico e à formulação e à implantação de políticas públicas dirigidas ao enfrentamento dos problemas sociais. Observa-se que a proposição de uma agenda para a indústria inclui ações, entre elas a formulação das políticas públicas, e discursos associados a outros 
universos de significação, independentes da preocupação em se obter riqueza e poder (Boltanski; Thévenot, 1991). A posse de capital produtivo e financeiro não dispensa a busca pelo capital social -a rede de relações que assegura uma posição de destaque na hierarquia de status, vantagens econômicas e capacidade de influência (Bourdieu, 1980; Coleman, 1990).

Valendo-se do arcabouço conceitual da pluralidade de lógicas de ação e de repertórios que configuram as "ordens de grandezas" (formas de coordenação e convenções que, uma vez legitimadas, se tornam reconhecidas como justificação), observa-se a presença de uma visão de mundo e de um projeto de futuro que impulsiona a elite industrial a uma postura militante de afirmação de uma "personalidade cívica", empenhada em legitimar os interesses da indústria sob o imperativo da realização do bem comum, um símbolo do "mundo cívico", uma das "convenções" ou ordens historicamente construídas (Boltanski; Thévenot, 1991). Apesar de ser inegável a preocupação com as finalidades materiais de sua base de representação, a dinâmica da instituição CNI não se reduz às escolhas e práticas demarcadas estritamente pela racionalidade instrumental (a relação entre fins e meios, típica do comportamento racional), pois visa também a outras conveniências sociais, tais como: a reafirmação de um padrão de sociabilidade e de uma condição de status; o interesse de difusão de sua visão de mundo; e o reforço da legitimidade social da própria instituição diante de seu "público" - grandes, médios, pequenos e microempresários - e, em conexão com esse público, frente ao conjunto da sociedade (Granovetter, 1985; Hall; Taylor, 1996).

Em síntese, o resultado da análise do material produzido pela CNI revela uma "agenda empresarial" cujo escopo extrapola os limites da racionalidade instrumental que garante a inserção e o reconhecimento dos empresários e executivos na vida dos negócios (posses materiais, sucesso econômico, poder e capacidades empreendedoras etc.). A lógica da ação utilitária (a defesa dos interesses econômicos e políticos) e tam- bém a busca do reconhecimento externo ao grupo de referência - a afirmação como ator relevante para o conjunto da sociedade e a legitimação da própria atividade econômica justificam a preocupação das elites empresariais em ocupar espaços na arena pública. Preocupamse essas elites com a defesa dos interesses do mundo dos negócios quando se propõem a potencializar a "[...] capacidade de tornar visível a agenda do setor e defendê-la frente às autoridades públicas, parlamentares, partidos, lideranças, formadores de opinião e da sociedade[...]", os atores que "[...] interferem, influenciam e decidem sobre as políticas públicas" (CNI, 2005c, p. 22). Mas vão além: consideram-se "agentes do desenvolvimento e da mudança", dentro e fora de suas empresas, e participantes ativos da formulação e da implantação das políticas públicas e da mobilização da sociedade em prol do desenvolvimento. Não é outro o teor do apelo da CNI (2006, p. 14) para que "[...] as forças políticas da nação e da sociedade civil alinhem-se em torno de uma agenda comum e desenvolvam um processo de negociação capaz de avançar a agenda modernizadora”. E essa conjunção de forças deve aproveitar os "momentos especiais", sobretudo aqueles de eleição, quando os governantes "têm o seu mais alto capital político" para apresentar e defender os seus projetos de governo.

\section{COMENTÁRIOS FINAIS}

Uma breve síntese dos enunciados deste artigo destaca, em primeiro lugar, a recorrente visão da educação como estratégia de racionalização na constituição e organização do mercado de trabalho e como eixo de sustentação do processo de desenvolvimento sustentável do ponto de vista econômico e social. Observa-se uma linha de continuidade, embora com singularidades impostas pelas diversas conjunturas, a respeito da relação entre educação, inovação e desenvolvimento, bem como ao papel assumido pelos empresários do setor industrial no desem- 
penho da economia, na constituição e organização do mercado de trabalho e na liderança da modernização da sociedade. A inserção privilegiada da indústria na ordem econômica transborda para outras esferas da vida social, convertendo-se em capital político e em fonte de legitimação social das atividades do mercado e das identidades empresariais.

O ethos fordista se atualiza, na medida em que essa construção se espalha por diversos setores da opinião pública, no discurso de diferentes segmentos sociais. Amplia-se o papel diretivo dos empresários na sociedade, em particular a sua capacidade de formulação e execução de políticas públicas: além da presença no debate de ideias, na formação da opinião pública, eles integram diversos arranjos sociais institucionalizados ou não, voltados para a promoção da educação, alçada à condição de via principal tanto para a inovação (e, portanto, para sustentar dinâmicas econômicas competitivas) quanto para o desenvolvimento social, via redução das desigualdades sociais.

O material discursivo analisado neste artigo indica que a investida empresarial no campo da educação alinha-se ao desenvolvimento de competências técnicas e sociais inerentes ao paradigma produtivo vigente, mas também configura uma estratégia político-argumentativa destinada a sustentar um padrão regulatório e um projeto de organização e modernização da sociedade. Por sua vez, a matriz de ideias e valores presente na retórica empresarial sinaliza a perenidade da tríade formada por socialização, regulação e legitimação na construção de uma ordem social a partir do universo da indústria.

Mas, para legitimar práticas e relações sociais, esse universo de significado precisa transcender a esfera das relações de mercado e os interesses específicos de determinados segmentos da sociedade e ser compartilhado pela maioria. A causa da educação é a síntese de uma complexidade de crenças e de significados coletivos: comporta um sentido econômico, suporte do crescimento da produção de riqueza, mas tam- bém um sentido político e ético-moral, expresso no crescimento intelectual, no reconhecimento de direitos, na inclusão social e na afirmação de identidades legítimas.

Texto recebido em 02 de abril de 2012 Aceito em 11 de setembro de 2012

\section{REFERÊNCIAS}

ARBIX, Glauco; DE NEGRI, João. A. A nova competitividade da indústria e o novo empresariado uma Hipótese de trabalho. São Paulo em Perspectiva, São Paulo, v. 19, n. 2, p. 2131, abr./jun., 2005. Disponível em: www.scielo.br/pdf/spp/ v19n2/v19n2a02.pdf. Acesso em: 5 dez. 2012.

BOLTANSKI, Luc; THÉVENOT, Laurent. De la justification: les économies de la grandeur. Paris: Gallimard, 1991.

; CHIAPELLO, Eve. Le nouvel esprit du capitalisme. Paris: Gallimard, 1999.

BOURDIEU, Pierre. Le capital social - notes privisoires. Actes de la recherche em sciences sociales, Paris, v. 31, n. 1, p. 2-3, jan., 1980.

2000 . Les structures sociales de l'économie. Paris: Seuil,

BRASIL. Brasil Maior. Inovar para competir. Competir para crescer. Plano 2011/2014. Brasília, 2011. Disponível em: www.brasilmaior.mdic.gov.br/wp-content/uploads/ cartilha_brasilmaior.pdf. Acesso em: 5 dez. 2012.

BRASIL. Ministério da Educação e do Desporto. Proposta de regulamentação das Diretrizes Curriculares Nacionais para a Educação Profissional. Brasília: MEC, 1997.

BRASIL. Ministério do Trabalho. Secretaria de Formação e Desenvolvimento Profissional. Educação profissional: um projeto para o desenvolvimento sustentado. Brasília, 1995.

BRASIL. Plano nacional de educação profissional: trabalho e empregabilidade. Brasília, 1996a.

BRASIL. Ministério da Educação e do Desporto. Reforma do ensino técnico. Brasília, 1996.

BRASIL. Secretaria de Formação e Desenvolvimento Profissional. Sistema público de emprego e educação profissional: implementação de uma política integrada. Brasília, 1996b.

BRESSER-PEREIRA, Luiz C.; DINIZ, Eli. Empresariado industrial, democracia e poder político. Novos estu. - Cebrap, São Paulo, n. 84, 2009. Disponível em: www.scielo.br/ pdf/nec/n84/n84a06.pdf. Acesso em: 6 dez. 2012.

COMISIÓN ECONÓMICA PARA AMÉRICA LATINA Y EL CARIBE (CEPAL).. Educación y conocimiento: eje de la transformación productiva con equidad. Santiago de Chile: UNESCO, 1992. Disponível em: http://unesdoc.unesco.org/ images/0015/001502/150253so.pdf. Acesso em: 6 dez. 2012.

CONFEDERAÇÃO Nacional da Indústria. Competitividade industrial: uma estratégia para o Brasil. Rio de Janeiro: CNI, 1988. . Rumo à estabilidade e ao crescimento. Rio de Janeiro: CNI, 1992.

Educação básica e formação profissional: uma visão dós empresários. In: REUNIÃO DE PRESIDENTES DE ORGANIZAÇÕES EMPRESARIAIS IBERO-AMERICA- 
NAS, 6., 1993, Salvador. Anais... Rio de Janeiro: CNI; SENAI, 1993.

Rumo ao crescimento: a visão industrial - sumário executivo. Rio de Janeiro: CNI, 1994.

. Modernização das relações de trabalho: princípios e objetivos. Rio de Janeiro: CNI, 1995.

. Competitividade: proposta dos empresários para a melhoria da qualidade da educação. Rio de Janeiro, 1996.

Emprego na indústria: evolução recente e uma agenda de mudanças. Rio de Janeiro: CNI, 1997.

. Competitividade e crescimento: a agenda da indústria. Brasília: CNI, 1998.

- A indústria e o Brasil: uma agenda para o crescimento. Brasília: CNI, 2002.

. Mapa estratégico da indústria: 2007-2015. Brasília CNI/DIREX, 2005c. Parte 1.

Mapa estratégico da indústria: 2007-2015. Brasília: CNI/DIREX, 2005a. Parte 2.

. Políticas públicas de inovação no Brasil: a agenda da indústria. Brasília: CNI, 2005b.

. Crescimento: a visão da indústria. Brasília: CNI, 2006

Educação para a nova indústria: uma ação para o desenvolvimento sustentável do Brasil. Brasília: CNI, 2007.

. Agenda legislativa da indústria 2008. Brasília: CNI, 2008.

. Agenda legislativa da indústria. Brasília: CNI, 2009.

Agenda legislativa da indústria 2010. Brasília: CNI, 2010a.

A indústria e o Brasil: uma agenda para crescer mais e melhor. Brasília: CNI, 2010b.

COLBARI, Antonia. Ética do trabalho: a vida familiar na construção da identidade profissional. São Paulo: Fundação Ceciliano Abel de Almeida: Letras \& Letras, 1995.

COLEMAN, James. Foundations of social theory. Cambridge: Harvard University, 1990.

CONDÉ, Eduardo S. Um mosaico ladrilhado: instituiç̃es, institucionalismos e complementaridades. In: SALGADO, Gilberto B. (Org.). Cultura e instituições sociais. Juiz de Fora: UFJF, 2006.

DINIZ, Eli; BOSCHI, Renato. Empresários, interesses e mercado: dilemas do desenvolvimento no Brasil. Belo Horizonte: UFMG; Rio de Janeiro: IUPERJ, 2004.

. A busca de um novo modelo econômico: padrões alternativos de articulação público-privado. Rev. Sociol. Polít., Curitiba, n. 14, p. 7-28, jun., 2000. Disponível em N www.scielo.br/pdf/rsocp/n14/a01n14.pdf. Acesso em: 6 dez. 2012.

As elites empresariais e a Nova República: corporativismo, democracia e reformas liberais no Brasil dos anos 90. Ensaios FEE. Porto Alegre, v. 17, n. 2 p. 55-79 Publicacoes/12783_Cached.pdf. Acesso em: 6 dez. 2012.

. Empresariado industrial, representação de interesses e ação política: trajetória histórica e novas configurações. Política \& Sociedade, Florianópolis, v. 9, n. 17, p. 101-139, out., 2010. Disponível em: www.periodicos.ufsc.br/ index.php/politica/article/view/15675/14196. Acesso em: 6 dez. 2012

. Reformas econômicas, elites empresariais e democracia no Brasil. In: KIRSCHNER, A. M.; GOMES, E. R. CAPPELLIN, Paola (Org.). Empresas, empresários globalização. Rio de Janeiro: Relume Dumará/FAPERJ, 2002. FLIGSTEIN, Neil. Habilidade social e a teoria dos campos.
Rev. adm. empres., São Paulo, v. 47, n. 2, p. 61-80, abr./ jun., 2007. Disponível em: www.scielo.br/pdf/rae/v47n2/ v47n2a13.pdf. Acesso em: 6 dez. 2012.

FONTENELLE, Isleide. A. Para uma crítica ao discurso da inovação: saber e controle no capitalismo do conhecimento. Rev. adm. empres., São Paulo, v. 52, n. 1, p. 100-108, jan./ fev., 2012. Disponível em: www.scielo.br/pdf/rae/v52n1/ 08.pdf. Acesso em: 6 dez. 2012.

FRANCO, Albano. Modernização e educação. Indústria e Produtividade, Rio de Janeiro, n. 278, p. 3, jul./ago. 1993.

GRAMSCI, Antonio. Americanismo e Fordismo. Maquiavel, a política e o estado moderno. Rio de Janeiro: Civilização Brasileira, 1984.

GRANOVETTER, Mark. Economics action and social structure: the problem of embeddedness. American Journal of Sociology, Chicago, v. 91, n. 3, p. 481-510, nov., 1985. Disponível em: http://glennschool.osu.edu/faculty/brown/ home/org\%20theory/readings/granovetter1985.pdf. Acesso em: 6 dez. 2012.

GUILHON, Maria V. M. Avaliação do Planfor entre a adesão de sujeitos sociais e a acomodação de interesses em torno da política: uma trajetória em direção à tecnificação. 2005. $272 \mathrm{f}$. Tese (Doutorado em economia aplicada) - Instituto de Economia, Universidade Estadual de Campinas, Campinas, 2005.

HABERMAS, Juger. Teoria de la acción comunicativa I : racionalidad de la acción y racionalización social. Madri: Taurus, 1987.

HALL, Peter; TAYLOR, Rosemary. Political science and the three new institutionalisms. Lothringer: Discussion Paper, 1996. Disponível em: www.mpifg.de/pu/mpifg_dp/dp966.pdf. Acesso em: 6 dez. 2012.

INSTITUTO HERBERT LEVY. Ensino fundamental $e$ competitividade empresarial: uma proposta para ação do governo. São Paulo: IHL, 1996.

INSTITUTO DE PESQUISA E ECONOMIA APLICADA (IPEA). Brasil: o estado de uma nação. Rio de Janeiro, 2006. Disponível em: www.ipea.gov.br/portal/images/stories/PDFs/ livros/Livro_estadonacao2007.pdf. Acesso em: 6 dez. 2012.

LÉVESQUE, Benoît. Contribuição da nova sociologia econômica para repensar a economia no sentido do desenvolvimento sustentável. RAE - Revista de Administração de Empresas, Rio de Janeiro, vol. 47, n. 2, p 49-60, 2007.

LÓPEZ-RUIZ, Osvaldo J. O 'ethos' dos executivos das transnacionais e o espírito do capitalismo. 2004. 385f. Tese (Doutorado em Ciências Sociais) - Departamento de Sociologia, Universidade Estadual de Campinas, Campinas, 2004.

MANCUSO, Wagner P. O Lobby da Indústria no Congresso Nacional: empresariado e política no Brasil contemporâneo. Revista de Ciências Sociais - DADOS, Rio de Janeiro, v. 47, n. 3, p. 505-547, 2004. Disponível em: www.scielo.br/pdf/ dados/v47n3/a03v47n3.pdf. Acesso em: 6 dez. 2012.

; OLIVEIRA, Amâncio J. de. Abertura econômica empresariado e política: os planos doméstico e internacional. Lua Nova, São Paulo, n. 69, p. 147-172, 2006. Disponível em: www.scielo.br/pdf/ln/n69/a07n69.pdf. Acesso em: 6 dez. 2012.

MARTINELLI, Alberto. O contexto do empreendedorismo. In: MARTES, Ana C. (Org.). Redes e sociologia econômica. São Carlos: EdUFScar, 2009.

OLIVEIRA, Ramon. Empresariado industrial e a educação profissional brasileira. Educ. Pesq., São Paulo, v. 29, n. 2 , jul./dez., 2003. Disponível em: www.scielo.br/pdf/ep/ v29n2/a04v29n2.pdf. Acesso em: 6 dez. 2012.

A divisão de tarefas na educação profissional brasileira. Cadernos de Pesquisa, São Paulo, n. 112, p. 185-203, mar., 2001. Disponível em: www.scielo.br/pdf/cp/n112/ 16108.pdf. Acesso em: 6 dez. 2012. 
PROGRAMA CIÊNCIA SEM FRONTEIRAS. Brasília:

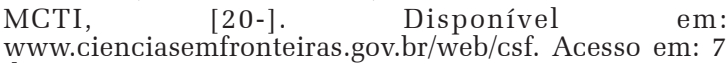
dez. 2012.

QUARTIERO, Elisa; BIANCHETTI, Lucídio (Org.). Educação corporativa: mundo do trabalho e do conhecimento: aproximações. São Paulo: Cortez, 2005.

RODRIGUES, José. O Moderno príncipe industrial: o pensamento pedagógico da Confederação Nacional da Indústria. Campinas: Autores Associados, 1998.

RUMMERT, Sonia. M. Educação e identidade dos trabalhadores: as concepções do capital e do trabalho. São Paulo: Xamã; Niterói: Intertexto, 2000.

SCHULTZ, Theodore W. Investment in human capital. American Economic Review, v. LI, n. 1, p. 1-17, mar., 1961.

- TOLIPAN, Ricardo. O capital humano: investimento em educação e pesquisa. Rio de Janeiro: Zahar, 1973.

SILVA, Maria V.; SOUZA, Silvana A. Educação e responsa- bilidade empresarial: "novas" modalidades de atuação da esfera privada na oferta educacional. Edu. Soc., Campinas, v. 30, n. 108, p. 779-798, out., 2009. Disponível em: www.scielo.br/pdf/es/v30n108/a0830108.pdf. Acesso em: 6 dez. 2012

SILVA FILHO, Horácio P. O empresariado e a educação. In: FERRETTI, João et al (Org.). Novas tecnologias, trabalho e educação: um debate multidisciplinar. 3. ed. Petrópolis: Vozes, 1996.

SOUZA, Maria I. Os empresários e a educação: IPES e a questão educacional após 1964. São Paulo: Cortez, 1981.

SWEDBERG, Richard. Sociologia econômica: hoje e amanhã. Tempo Soc., São Paulo, v. 16, n. 2, p. 7-34, nov, 2004. Disponível em: www.scielo.br/pdf/ts/v16n2/v16n2a01.pdf. Acesso em: 6 dez. 2012.

UNITED NATIONS. Economic Commission for Latin America and the Caribbean. (CEPAL). Transformación productiva con equidad: la tarea prioritaria del desarrollo de América Latina y el Caribe en los años noventa. Santiago de Chile, 1996. 


\section{EDUCATION AND LABOR IN COMPANY RHETORIC: update on the Ford ethos}

\author{
Antonia de Lourdes Colbari
}

This study proposal is based on a historic thesis which today has taken on new meanings and has become a panacea. It deals with the relationship among education, development and modernization of society, a triad which demands on an ever greater scale the encouragement of education, innovation and social inclusion. The empirical support for this analysis was extracted from technical documents from the CNI (National Confederation of Industries) and considered emblematic for making explicit the configuration of the propositions and meaningful traits of the system of corporate beliefs and values of Brazilian industries. Despite the conjunctural singularities, the result showed evidence of a continuum in the relationship between education, innovation and development, and also of the role that this business sector seeks to play in the economy, in the constitution, and in the organization of the labor market and in the processes of social modernization.

KEY wORDS: Education. Labor. Development. Company institutions. Ford ethos.

\section{ÉDUCATION ET TRAVAIL DANS LA RÉTHORIQUE DES ENTREPRISES: mise à jour de l'ethos fordien}

\author{
Antonia de Lourdes Colbari
}

Le propos de cette étude vient d'une ancienne thèse qui, à l'heure actuelle, prend un nouveau sens et devient une espèce de panacée. Il s'agit de la relation entre éducation, développement et modernisation de la société, triade qui exige à une échelle de plus en plus grande la promotion de la scolarité, de l'innovation et de l'inclusion sociale. D'un point de vue empirique, la base de l'analyse est constituée de documents techniques publiés par la CNI (Confédération Nationale de l'Industrie) et considérés emblématiques pour expliquer la configuration des propositions et des principaux traits qui caractérisent les croyances et les valeurs des industriels qui dirigent les entreprises brésiliennes. En dépit des particularités conjoncturelles, le résultat met en évidence la continuité d'une ligne de conduite quant à la relation entre l'éducation, l'innovation et le développement mais aussi quant au rôle que les industries souhaitent jouer dans l'économie, la constitution et l'organisation du marché du travail et dans les processus de modernisation sociale.

Mots-CLÉs: Éducation. Travail. Développement. Institutions entrepreneuriales. Ethos fordiste

Antonia de Lourdes Colbari - Doutora em Sociologia pela Sociedade Brasileira de Instrução - SBI/ IUPERJ. Professora associada, nível 4 da Universidade Federal do Espírito Santo e Bolsista de Produtividade em Pesquisa do CNPq, nível 2. Atua na área de Sociologia, com ênfase em Sociologia do Trabalho e das Organizações, desenvolvendo pesquisas principalmente nos seguintes temas: trabalho nas organizações contemporâneas; educação e qualificação profissional; empreendedorismo e cultura do trabalho. Publicações recentes: A categoria dos auditores fiscais da receita federal do Brasil. A (des)construção da identidade profissional. Cadernos EBAPE.BR (FGV), v. 8, p. 3, 2010; A CUT-ES e o Movimento Sindical na Década de 80. Sinais (UFES), v. 1, p. 167-275, 2010. 